\title{
Child Health Policies in India: Moving from a Discernible Past to a Promising Future
}

\author{
Manu Raj Mathur ${ }^{1} \cdot$ K. Srinath Reddy ${ }^{1}$ \\ Received: 10 April 2019 / Accepted: 11 April 2019 / Published online: 29 April 2019 \\ (C) Dr. K C Chaudhuri Foundation 2019
}

Children up to $14 \mathrm{y}$ of age comprise almost one-third (29.5\%) population of India [1]. Protecting the health of this largest demographic group requires sound policies and programmes as these children are the future work force and intellectual powerhouse of our country. They will be the flagbearers of sustainable development in India.

India has traversed an eventful journey of evolution and implementation of child health care policies and programmes since independence. The vision and focus of these programmes has changed over the years, as understanding of child health grew. India was the first country in the world to roll out a National Family Planning Programme in the year 1952 with the aim of lowering the fertility rate and controlling the growth of population. Health of infants and newborns formed a relatively minor component of this programme. Later, the Government of India came up with the National Policy for Children in 1974 to prioritise child health, nutrition, orphan and destitute children and children with disabilities and to implement laws for the same [2].

In 1977 , the family planning program transitioned into Family Welfare Programme. Maternal and child health care became an integral part of this programme with the recognition that reduction in infant and child mortality is directly proportional to reduction in birth rate [3]. With an increased thrust on the health of children, the Expanded Programme on Immunisation (EPI) was launched in the year 1978 to provide vaccination against diphtheria, pertussis, tetanus, poliomyelitis, measles and tuberculosis [4]. In order to overcome the inadequacies of the EPI, the Universal Immunisation Programme (UIP) was launched by Government of India. This initially was launched in a phased manner and became operational in all districts by the year 1989-90 [5].

K. Srinath Reddy

ksrinath.reddy@phfi.org

1 Public Health Foundation of India, New Delhi, India
Acting on a WHO and UNICEF report which reported that about 0.5 million women die each year during pregnancy and child birth, a Child Survival and Safe Motherhood (CSSM) programme was initiated by Government of India in 1992 with the objective of reducing infant and maternal mortality rates [6]. Policy now aimed at reinforcing the Oral Rehydration Therapy (ORT) and Acute Respiratory Infection (ARI) programmes for control of diarrhea and pneumonia in children and control of anemia in pregnant women [4]. Government also introduced the Reproductive and Child Health (RCH) Programme Phase I during 1997-98 to fulfil the unmet need for family welfare services in the country, especially among the poor and under-served. It was integrated with CSSM in 2005 [7]. Experience from RCH Phase I determined the contours of RCH II, which was a paradigm shift from 'one size fits all' design to an approach where sub-national requirements, capacities and performances were considered and steered to stimulate demand for services [2]. RCH Phase II adopted Integrated Management of Neonatal and Childhood Illnesses (IMNCI) in 2005. IMNCI consolidated preventive and curative elements to improve the skills of healthcare staff, overall health systems and family and community health practices [8].

The government launched National Rural Health Mission (NRHM) in 2005 to focus on Reproductive, Maternal, Newborn, Child Health and Adolescent (RMNCH+A) services, with the adolescent health component being a relatively recent addition. Its objectives were to improve maternal and child health through a continuum of care and lifecycle approach. Further, it focused on improving linkages between various levels of health care systems and strengthening referral systems. This was later subsumed in National Health Mission in 2013, along with the proposed National Urban Health Mission, to provide a remarkable increase in coverage and quality of health care for mothers and children. Under National Health Mission (NHM) the provision of health care to children particularly in rural areas is given priority attention [9]. The impact of these concerted efforts was clearly visible 
on the under 5 mortality rate which came down from 111 per 1000 live births in 1990 to 39 in 2018 [10]. We now need to be on track to reach the Sustainable Development Goals (SDG) target of 25 by 2030 .

Currently, there are various interventions being implemented to improve the health of children. These are a) Janani Shishu Suraksha Karyakaram which entitles all pregnant women delivering in public health institutions to absolutely free and no expense delivery including Cesarean section; $b$ ) India Newborn Action Plan to reduce neonatal mortality and stillbirths; c) Integrated Action Plan for Pneumonia and Diarrhea launched in four states with highest child mortality (UP, MP, Bihar and Rajasthan); d) Village Health and Nutrition Days organized for imparting nutritional counseling to mothers and to improve child care practices; e) Mother and Child Tracking System to ensure registration and tracking of all pregnant women and newborn babies so that provision of regular and complete services to them can be ensured; f) Rashtriya Bal Swasthya Karyakram to provide comprehensive care to all the children in the age group of $0-18 \mathrm{y}$ in the community (with a 4D thrust to screen for and manage birth Defects, Diseases, Deficiencies and Developmental delays, including disabilities); g) National Iron Plus Initiative for the prevention of anemia among the vulnerable age groups, women of reproductive age, pregnant and lactating women; and $\mathrm{h}$ ) Mission Indradhanush to achieve $90 \%$ full immunization coverage of India by year 2020.

Undernutrition of children has been a major challenge to child survival, growth and cognitive development. The Integrated Child Development Scheme (ICDS), launched in 1975 , has addressed the nutrition and education needs of preschool children and has evolved over time to cover the $0-6$ y age range. Poshan Abhiyan, the recently launched nutrition mission, aims to improve the nutritional status of children in that age range, adolescent girls, pregnant and lactating women [11]. While the thrust to eliminate undernutrition is essential, the rising threat of overweight and obesity among children and adolescents needs to be addressed through programmes promoting healthy nutrition and physical activity. Otherwise, the danger of early onset of non-communicable diseases looms large [12]. A life course approach to health and nutrition must become a feature of our policy and programme response to the health transition that is underway.

This special issue brings together many scholarly articles on child health, tracing the adversities and accomplishments that marked the journey of the last $50 \mathrm{y}$. The need for modifications in the ICDS is discussed [13], as are methods for strengthening the School Mid Day Meal Programme [14]. Even as a strong case is made for discontinuation of the High Dose Vitamin A distribution in India, strategies for the prevention and control of Vitamin A deficiency are analysed and emphasised as an urgent need [15]. Redesigning of IMNCI is recommended and newer approaches are proposed for invigorating the National Immunisation Programme [16, 17]. Newborn health, a matter of continuing concern even as under- 5 mortality declines, is discussed in the context of the evolving $\mathrm{RMNCH}+\mathrm{A}$ programme [18]. Even as this programme brings attention to adolescent health, the problem of anemia among children and adolescents poses challenges which are identified and addressed in another review [19]. An article on interventions for prevention and control of epidemic of vitamin D deficiency is also included [20]. Together, these articles capture the experiences, achievements and the unmet gaps in the national programmes for child health and nutrition. Distilling the lessons gathered over the past half century, they light up the path we must follow in the next decade to reach the SDGs by 2030 .

\section{Compliance with Ethical Standards}

Conflict of Interest None.

\section{References}

1. Ministry of Home Affairs, Government of India. Office of the Registrar General \& Census Commissioner, India. Census Data 2011; 2011. Available at: http://censusindia.gov.in/. Accessed 10 April 2019.

2. Jagannadham V. National policy for children. Indian J Publ Admin. 2017;25:533-48.

3. Department of Health \& Family Welfare, Government of India. Child Health Programme in India; 2010. Available at: http:// mohfw.nic.in/. Accessed 10 April 2019.

4. Keja K, Chan C, Hayden G, Henderson RH. Expanded programme on immunization. World Health Stat Q. 1988;41:59-63.

5. Ministry of Health Family and Welfare. Universal Immunisation Programme. National Health Portal of India; 2018. Available at: https://www.nhp.gov.in/universal-immunisation-programme. Accessed 10 April 2019.

6. Ghosh S. Child survival and safe motherhood -the hard road ahead. 1987. Available at: http://nutritionfoundationofindia.org/pdfs/ BulletinArticle/Pages_from_nfi_04_94_2.pdf. Accessed 10 April 2019.

7. Paruthi R, Dutta PK. Reproductive and child health programme. Indian J Public Health. 2002;46:72-7.

8. World Health Organization. WHO division of child health and development. Integrated management of childhood illness: conclusions. Bull World Health Organ. 1997;75:119-28.

9. Ministry of Health Family and Welfare. National Health Mission; 2017. Available at: http://nhm.gov.in/nhm.html. Accessed 10 April 2019.

10. Institute for Health Metrics and Evaluation. GBD Foresight. IHME Viz Hub. 2018 University of Washington; 2017. Available at: https://vizhub.healthdata.org/sdg/. Accessed 10 April 2019.

11. Poshan Abhiyaan - PM's overarching scheme for holistic nourishment. National Portal of India; 2018. Available at: https://www. india.gov.in/spotlight/poshan-abhiyaan-pms-overarching-schemeholistic-nourishment. Accessed 10 April 2019.

12. World Health Organization. Obesity and overweight. World Health Fact Sheet; 2006. p. 1-3. Available at: http://www.who.int/ mediacentre/factsheets/fs311/en/. Accessed 10 April 2019. 
13. Aggarwal P, Kakkar R. National nutrition strategy: the needed timely modification to make integrated child development scheme more effective. Indian J Pediatr. 2019. https://doi.org/10.1007/s12098019-02869-9.

14. Ramachandran P. School mid-day meal programme in India: past, present, and future. Indian J Pediatr. 2019. https://doi.org/10.1007/ s12098-018-02845-9.

15. Greiner T, Mason J, Benn CS, Sachdev HPS. Does India need a universal high-dose vitamin A supplementation program? Indian J Pediatr. 2019. https://doi.org/10.1007/s12098-018-02851-x.

16. Aneja S. Integrated management of newborn and childhood illness (IMNCI) strategy and its implementation in real life situation. Indian J Pediatr. 2019. https://doi.org/10.1007/s12098-019-028702 .

17. Bhadoria AS, Mishra S, Singh M, Kishore S. National immunization programme - mission indradhanush programme: newer approaches and interventions. Indian J Pediatr. 2019. https://doi. org/10.1007/s12098-019-02880-0.

18. Ramji S, Jain A. National program for RMNCH + A: newer strategies for improving the newborn health in India. Indian J Pediatr. 2019. https://doi.org/10.1007/s12098-019-02867-x.

19. Kapil U, Kapil R, Gupta A. Prevention and control of anemia amongst children and adolescents: theory and practice in India. Indian J Pediatr. 2019. https://doi.org/10.1007/s12098-019-029325 .

20. Marwaha RK, Dabas A. Interventions for prevention and control of epidemic of vitamin D deficiency. Indian J Pediatr. 2019. https:// doi.org/10.1007/s12098-019-02857-z.

Publisher's Note Springer Nature remains neutral with regard to jurisdictional claims in published maps and institutional affiliations. 